\title{
Parkinson Hastalığında Kırılganlık ile Fiziksel Fonksiyon Arasındaki İlişki
}

\author{
Sevim ACARÖZ CANDAN ${ }^{1}$, Tuba Şaziye ÖZCAN 國 ${ }^{2}$
}

\section{ÖZ}

Amaç: Bu çalışma, Parkinson hastalığında (PH) kırılganlık ile fiziksel fonksiyon arasındaki ilişkiyi belirlemeyi ve kırılganlık fenotiplerine göre fiziksel fonksiyon durumunu incelemeyi amaçlamaktadır.

Gereç ve yöntemler: Kesitsel tipteki bu çalışmaya PH tanısı almıș 68 hasta (21 kadın, 47 erkek) dahil edildi. Kırılganlık FRAGIL ölçeği ile, fiziksel fonksiyon ise kısa fiziksel performans bataryası (KFPB) ve dijital el dinamometresi ile değerlendirildi. FRAGIL ölçeği puanına göre hastalar kırılgan olmayan, kırılganlık öncesi dönemde olan ve kırılgan olan Parkinson hastaları olmak üzere 3 gruba ayrıldı.

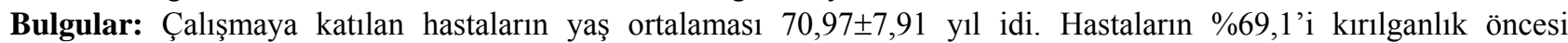
dönemde iken, \%22,1'inde kırılganlık mevcut, \%8,8'inde kırılganlık yoktu. KFPB puanı ve el kavrama kuvveti sirasiyla kırllgan olmayan grupta $10,17 \pm 0,41$ ve $18,67 \pm 2,58$, kırllganlık öncesi dönemde olan grupta $8,21 \pm 2,34$ ve $14,06 \pm 5,97$ iken krrılgan olan grupta $5,73 \pm 3,67$ ve $12,47 \pm 7,44$ idi. Gruplar arasinda toplam KFPB puanı ve KFPB alt boyutları açısından fark tespit edildi $(p<0,01)$. Kırılgan olan grupta KFPB puanları daha düşüktü $(p<0,01)$. El kavrama kuvveti gruplar arasında benzerdi ( $p>0,05)$. KFPB puanları ile FRAGIL ölçeği skoru arasında negatif yönlü ilişki tespit edildi $(p<0,05)$. El kavrama kuvveti ile FRAGIL ölçeği skoru arasında ilişki saptanmadı $(p>0,05)$

Sonuç: Bu çalışma Parkinson hastalarının kırılganlık açısından risk altında olduğunu gösterdi. Parkinson hastalarında kırılganlık durumuna ve şiddetine göre alt ekstremite fonksyionu, denge becerileri ve yürüme hızı azalmakta, üst ekstremite fonksiyonu ise kırılganlık durumuna göre değişmemektedir. PH'nda kırılganlık ile ilişkili olan alt ekstremite fonksiyonu, denge becerileri ve yürüme hızı gibi fiziksel fonksiyon parametrelerine yönelik olan uygulamalar/yaklaşımlar kırılganlığın önlenmesi, geciktirilmesi ve/veya etkilerinin azaltılmasında faydalı olabilir. Anahtar Kelimeler: Parkinson hastalığı; kırılganlık; fiziksel fonksiyonel performans; postural denge; el gücü.

\section{The Relationship between Fragility and Physical Function in Parkinson's Disease} ABSTRACT

Aim: This study aims to determine the relationship between fragility and physical function in Parkinson's disease (PD) and to investigate the physical function status according to the fragilty phenotypes.

Material and methods: In this cross-sectional study, 68 patients (21 females, 47 males) diagnosed with PD were included. Fragility was assessed by the FRAGIL scale, and physical function by the short physical performance battery (SPPB) and digital hand dynamometer. According to the FRAGIL scale score, the patients were divided into three groups: non-fragil, pre-fragil, and fragil patients with PD.

Results: The mean age of the patients in this study was $70.97 \pm 7.91$ years. While $69.1 \%$ of the patients were in the prefragil period, $22.1 \%$ of them were fragil, and $8.8 \%$ of them were non-fragil. SPPB score and handgrip strength were $10.17 \pm 0.41$ and $18.67 \pm 2.58$ in the non-fragil group, $8.21 \pm 2.34$ and $14.06 \pm 5.97$ in the pre-fragil group, while it was $5.73 \pm 3.67$ and $12.47 \pm 7.44$ in the fragil group, respectively. There was a difference between the groups in terms of total SPPB score and SPPB sub-dimensions $(\mathrm{p}<0.01)$. SPPB scores were lower in the fragil group $(\mathrm{p}<0.01)$. Handgrip strength was similar between the groups ( $p>0.05$ ). A negative correlation was found between SPPB scores and the FRAGIL scale score $(\mathrm{p}<0.05)$. There was no relationship between handgrip strength and FRAGIL scale score ( $\mathrm{p}>$ $0.05)$.

\footnotetext{
1 Ordu Üniversitesi, Sağlık Bilimleri Fakültesi, Fizyoterapi ve Rehabilitasyon Bölümü, Ordu, Turkey
}

2 Ordu Üniversitesi, Tıp Fakültesi, Nöroloji Anabilim Dalı, Ordu, Turkey 
Conclusion: This study showed that patients with PD were at risk for fragility. The lower extremity function, balance skills, and walking speed decrease in patients with PD according to the fragility status and severity of their fragility, while the upper extremity function does not change according to their fragilty status. Interventions/approaches related to physical function parameters such as lower extremity function, balance skills, and gait speed, which are associated with fragilty in PD may be useful in preventing, delaying, and/or reducing the effects of fragilty.

Keywords: Parkinson disease; fragility; physical functional performance; postural balance; hand strength. GİRIŞ

Kırılganlık, birden çok organ veya sistemde fonksiyonel yetersizliğe bağlı olarak ortaya çıkan fizyolojik rezervde azalma ve stres faktörlerine karşı direnç kaybı şeklinde tanımlanan geriatrik bir semptomdur (1). Kirılganlık birçok klinik bulguyu (kilo kaybı, kas gücü kaybı, tükenmişlik, fiziksel güç ve aktivitede azalma, yürüme hızında yavaşlama, yorgunluk gibi) içermekle birlikte yaşlılarda düşme, disabilite, hastaneye yatış ve mortalite durumları ile de yakından ilişkilidir $(2,3)$. Kırılganlığın patogenezinde inflamatuar, hormonal ve beslenme değişikliklerine ilişkin süreçlerin etkili olduğu düşünülmektedir (4). Kırılganlığın yaş ile doğru orantılı arttığı ve 65 yaş ve üzeri bireylerin \%4-59'unda kırılganlık saptandığı bildirilmiştir (5). Ayrıca kırılganlık görülme oranı yaşlılarda eşlik eden kronik hastalıklara bağlı olarak da artmaktadır (6).

Parkinson hastalığ 1 (PH), substantia nigrada dopaminerjik nöronların ölümü ile karakterize, inflamatuar süreçlerin hakim olduğu nörodejeneratif bir hastalıktır. Parkinson hastalarında ortaya çıkan motor ve motor olmayan semptomların kümülatif etkisi bu hasta populasyonunda kırılganlık açısından artırılmış ve hızlandırılmış bir risk ortaya çıkarmaktadır. PH'nda kırılganlık üzerine yapılan prevelans çalışmalarında PH'nda kırılganlık görülme oranının \%29 ile \%67 arasında değiştiği gösterilmiştir (7). Kadın Parkinson hastalarının erkek Parkinson hastalarına göre kırılganlığa daha yatkın oldukları ve hastalık şiddetine paralel olarak kırılganlığın artabileceği bildirilmiştir (8). Bununla birlikte kırılgan Parkinson hastalarının daha yüksek hastalık semptom skorlarına sahip olduğu, kırılganlığın neden olduğu fonksiyonel düşüşün yanlış yorumlanıp hastalık semptomlarına atfedildiği ve bunun sonucunda PH'nda kırılganlığın göz ardı edildiği, erken dönemde tanılanmasının güç olduğu görülmektedir (9). Ayrıca PH'nda yaşam kalitesi ile kırılganlık fenotipleri arasındaki ilişki ve yaşam kalitesinin daha çok fiziksel fonksiyondan etkilendiği bildirilmektedir (8). Yaşam kalitesi üzerindeki olumsuz etkisi de göz önünde bulundurularak Parkinson hastalarında kırılganlık ile fiziksel fonksiyon arasındaki ilişkinin aydınlatılması gerekliliği son dönemdeki araştırmalarda vurgulanmaktadır. PH'nda kırılganlık ile ilgili yapılmış çalışmalar incelendiğinde Parkinson hastalarında görülen kırılganlık ile fiziksel fonksiyon arasındaki ilişkinin sadece bir çalışmada kırılganlık ve mobilite arasındaki ilişki açısından ele alındığ görülmektedir. 2019 yılında yayınlanan bu araştırma, Parkinson hastalarında kırılganlık ile zamanlı kalk ve yürü testi (ZKYT) arasında doğrusal bir ilişki olduğunu saptamış ve testin 15,36 saniyeden daha uzun zamanda tamamlanmasını PH'nda kırılganlık açısından risk olarak tanımlamıştır (10). Ancak fiziksel fonksiyonun sadece mobilite boyutunun ele alınması, kardinal bulguları arasında postural instabilite ve bradikinezi olan PH için yeterli olmamaktadır. Fiziksel fonksiyonun mobilitenin yanında denge, yürüme hızı, alt ekstremite ve üst ekstremite fonksiyonu açısından da incelenmesi gerekmektedir. $\mathrm{Bu}$ yüzden bu çalışma Parkinson Hastalarında fiziksel fonksiyon ile kırılganlık arasındaki ilişkiyi denge, yürüme hızı, alt ekstremite ve üst ekstremite fonksiyonu açısından incelemek amacı ile planlanmıştır. Bu çalışmada ilişkinin yanında kırılganlık fenotiplerine göre Parkinson hastalarının fiziksel fonksiyon durumları da incelenecektir.

\section{GEREÇ VE YÖNTEMLER}

$\mathrm{Bu}$ çalışma, Ordu Üniversitesi Eğitim ve Araştırma Hastanesi Hareket Bozuklukları Polikliniğinde Eylül 2019-Mart 2020 tarihleri arasında gerçekleştirildi. Kesitsel olarak planlanan çalışmamıza dahil edilme kriterlerini karşılayan 68 Parkinson hastası alındı. Herhangi bir örneklem seçim yöntemi kullanılmaksızın belirtilen zaman aralığında evrenin tamamına ulaşılması hedeflendi. Dahil edilme kriterleri; nörolog tarafindan "Birleşik Krallık Parkinson Hastalığı Derneği Beyin Bankası" tanı kriterlerine göre İdiyopatik Parkinson Hastalığı tanısı almak (11), 55 yaşın üzerinde olmak, bilişsel durumu iyi olmak (Standardize Mini Mental Testten 24 ve üzeri puan almak), çalışmaya katılmaya gönüllü olmak ve çalışma kapsamında uygulanacak performans testlerini bağımsız gerçekleştirebilmek olarak belirlendi. Fiziksel fonksiyonu etkileyebilecek ek bir ortopedik ve/veya nörolojik problemi, görme sorunu, periferik vestibüler problemi olan ve kırılganlığa neden olabilecek malignite öyküsü, ileri evre konjestif kalp yetmezliği, kronik böbrek hastalığı bulunan bireyler ise çalışma dışında bırakıldı. Helsinki Deklarasyonu kriterlerine uygun gerçekleştirilen çalışmada bireylerden yazılı onam alındı. Çalışmanın metodolojisi Ordu Üniversitesi Klinik Araştırmalar Etik Kurulu'nca 25/04/2019 tarihli toplantıda değerlendirilerek 2019-66 karar sayısı ile etik olarak onaylandı.

Katılımcıların sosyodemografik bilgileri (ad, soyad, yaş, boy, kilo, cinsiyet vb.) sağlık-hastalık bilgileri (hekim tarafından tanısı konulan hastalıklar, $\mathrm{PH}$ tanısı alma zamanı, PH'nin klinik tipi, geçirilen ameliyatlar, kullanılan ilaçlar vb.) araştırmacılar tarafindan hazırlanmış yapılandırılmış hasta bilgi formu ile yüz yüze olacak şekilde alındı. Hastaların klinik değerlendirmesi hastanın "açık" olduğu, ilaç etkin dönemde (ilaç alımından 2 saat sonra) çalışmanın araştırmacılarından olan bir fizyoterapist tarafından gerçekleştirildi. Hastalığın şiddeti modifiye Hoehn \& Yahr evrelemesi ile belirlendi. Sıfır ile beş arasında derecelendirme yapan evreleme sistemine göre evrenin yükselmesi hastalık şiddetinin arttığının göstergesi olarak yorumlandı (12).

Hastaların kırılganlık durumlarını belirlemek için Türk popülasyonundaki yaşlı bireyler için kırılganlığ değerlendirmede geçerli ve güvenilir bir ölçüm yöntemi olduğu bilinen FRAGIL ölçeği kullanıldı (13). Bu ölçek bireyin yorgunluk durumunu, direncini, mobilitesini, kilo kaybını ve eşlik eden diğer hastalıklarını sorgulayan, 5 maddeden oluşan bir ölçek olup her madde 0 veya 1 puan 
olarak puanlanmaktadır. Ölçekten alınan toplam puana göre bireyler dinç ( 0 puan, non-fragil), kırılganlık öncesi dönem (1-2 puan, pre-fragil) ve kırılgan ( $>2$ puan, fragil) olarak gruplandırıldı (14).

Katılımciların fiziksel fonksiyonu, kısa fiziksel performans bataryası (KFPB) ve el kavrama kuvveti ile değerlendirildi. KFPB toplum içerisinde yaşayan yaşlılarda fiziksel fonksiyonu ölçmede sıklıkla kullanılan bir yöntemdir (15). KFFB; alt gövde fonksiyonunu değerlendiren üç objektif (4 metre yürüme, sandalyeden kalkma ve ayakta durma testleri) testten oluşmaktadır. Her test 0 ile 4 arasında puanlanırken testten maksimum alınabilecek puan 12'dir. Testten alınan puanın artması fiziksel fonksiyonun iyi olduğunu göstermektedir (16). 4 metre yürüme testinde bireyin 4 metreyi yürüme zamanı ve sandalyeden kalkma testinde ise ellerini kullanmaksızın sandalyeden beş defa kalkıp oturduğu süre saniye cinsinden belirlenerek uygun test puanı verildi. Ayakta durma testi ise denge odaklı olup ayaklar yanyana, ayaklar topuk-parmak ucu (tandem pozisyonu) ve ayaklar yarı topuk-parmak ucu pozisyonunda (yarı tandem pozisyonu) 10 saniye dengeyi koruyabilme becerisini değerlendirdi. Testleri tamamlama ya da pozisyonu koruyabilme sürelerine göre her test için 0 ile 4 puan arasinda uygun puan verildi ve toplam test puanı hesapland1. El kavrama kuvveti, üst ekstremite fonksiyonunu değerlendirmek için dijital el dinamometresi (Baseline LITE el dinamometresi, USA) ile belirlendi. Ölçüm, Amerikan El Terapistleri Derneği'nin önerdiği pozisyonda gerçekleştirildi (17) ve ölçüm için dinamometrenin sıkma kolu ikinci kademede olacak şekilde ayarlandı (18). Katılımcılardan dinamometreyi mümkün olduğunca kuvvetle sıkmaları istendi ve sonuç kilogram cinsinden kaydedildi.

\section{İstatistiksel Analiz}

Elde edilen veriler IBM SPSS version 20,0 (IBM SPSS, Türkiye) ile analiz edildi. Değişkenlerin normal dağılıma uygunluğu Kolmogorov-Smirnov testi ile incelendi. Sürekli değişkenlere ilişkin veriler ortalama \pm standart sapma; kategorik değişkenlere ilişkin veriler ise n (\%) şeklinde verildi. FRAGIL ölçeği puanına göre katılımcılar kırılgan olmayan, kırılganlık öncesi dönemde olan ve kırılgan bireyler olarak 3 gruba ayrıldı. Kırılgan olmayan gruptaki kişi sayısı göreceli olarak az olduğu için değişkenlerin normal dağılım göstermesine karşın nonparametrik testler kullanılarak gruplar arası fark test edildi. KFPB ve el kavrama kuvveti test sonucu açısından gruplar arasındaki fark Kruskal Wallis- $\mathrm{H}$ testi ile kategorik değişkenler açısından fark ise Ki Kare testi ile belirlendi. Kruskal Wallis-H testi sonrasında farkın hangi gruptan kaynaklandığını belirlemek üzere post-hoc analizi olarak Mann-Whitney $U$ testi kullanıld. Kırılganlık ve fiziksel fonksiyon arasındaki ilişki Pearson korelasyon analizi ile incelendi. İstatistiksel anlamlılık düzeyi $\mathrm{p}<0,05$ olarak kabul edildi.

\section{BULGULAR}

Çalışmaya yaş ortalaması 70,97 $\pm 7,91$ yıl olan 68 Parkinson hastası katıldı. Katılımcıların \%30,9'u kadın, $\% 69,1$ 'i erkekti. Hastaların \%17,6's1 tremor baskın tipte, \%29,4'ü akinetik-rijit tipte, \%52,9'u mikst tipte idi. Hastaların mH\&Y ortalaması 2,15 $\pm 0,94$ idi. Hastalık süresi ortalama $84,41 \pm 62,34$ ay idi. Katılımcıların \%8,8'i kırılgan olmayan, \%69,1'i kırılganlık öncesi dönemde olan, \%22,1'i kır1lgan bireylerden oluşmaktaydı. Kırılganlık fenotipine göre bireylerin sosyodemografik ve klinik özelliklerinin karşılaştırılması Tablo 1'de sunuldu. Kırılganlık fenotiplerine göre 3'e ayrilan gruplar arasında hastalık süresi, $\mathrm{mH \& Y}$ evrelemesi ve hastalığın klinik alt tiplerinin dağılımı açısından fark bulundu $(\mathrm{p}<0,01)$. Yapilan post-hoc testlerde farkın kırılgan gruptan kaynaklandığ Buna göre; kırılgan Parkinson hastalarında $\mathrm{mH} \& \mathrm{Y}$ ortalaması kırılgan olmayan gruptan daha yüksekti $(\mathrm{p}=0,009)$, hastalık süresi kırılgan olan grupta kırılganlık öncesi dönemde olan ve kırılgan olmayan gruba göre daha kısaydı (sırasiyla $p=0,002$ ve $p=0,006$ ) ve kirılgan Parkinson hastalarında akinetik-rijit tip PH dağılımı kırılgan olmayan ve kırılganlık öncesi dönemde olan gruba göre daha fazlayd $(\mathrm{p}=0,001 \mathrm{ve} \mathrm{p}<0,001)$.

Hastaların KFPB toplam puan ortalamalarının 7,84 \pm 2,86, el kavrama kuvveti ortalamalarının 14,12 $\pm 6,25 \mathrm{~kg}$ olduğu görüldü. Kırılganlık fenotiplerine göre fiziksel fonksiyon puan ortalamalarının gruplar arasındaki karşılaştırma sonuçlarına Tablo 2'de yer verildi. Analiz sonuçlarına göre gruplar arasında KFPB toplam puan, KFPB alt ekstremite fonksiyonu puan1, KFPB denge puanı ve KFPB yürüme hızı puanı açısından anlamlı farklılık saptand $1(\mathrm{p}<0,01)$. KFPB toplam puan ortalamas1 kırılgan Parkinson hastalarında kirılgan olmayan grup ortalamasından daha düşüktü $(\mathrm{p}=0,008)$. Kırılganlık öncesi dönemde olan grubun KFPB toplam puan ortalamaları ile kirılgan olmayan ve kirılgan grubun ortalamaları benzerdi ( $p=0,254$ ve $p=0,056$ ). KFPB alt boyutları tek tek analiz edildiğinde alt ekstremite fonksiyon puan ortalamasının kırılgan olmayan grupta, kırılgan ve kırılganlık öncesi dönemde olan Parkinson hastalarının ortalamalarından daha yüksek olduğu görüldü $(p=0,008$ ve $p=0,016)$. Kırılgan grup ile kırılganlık öncesi dönemde olan grubun alt ekstremite fonksiyonu puan ortalamaları benzerdi $(p=1,000)$. KFPB denge puan ortalaması kırılgan Parkinson hastalarında kırılgan olmayan hastalara göre daha düşük iken ( $\mathrm{p}=0,010)$, kırılgan Parkinson hastaları ile kırılganlık öncesi dönemde olan hastaların denge puan ortalamaları benzerdi $(p=0,096)$. Ayrica kırılgan olmayan grup ile kırılganlık öncesi dönemde olan grubun denge durumları arasında fark yoktu ( $\mathrm{p}=0,207)$. KFPB yürüme hızı puanı kırılgan Parkinson hastalarında kırılganlık öncesi dönemde olan hastalardan daha düşüktü $(\mathrm{p}<0,001)$. Yürüme hızı puanı açısından kırılgan olmayan grup ile kırılgan ve kırılganlık öncesi dönemde olan grup arasında fark yoktu $(\mathrm{p}=0,266$ ve $\mathrm{p}=1,000)$.

Katılımcıların bazı sosyodemografik, hastalık özellikleri ve fiziksel fonksiyon test sonuçları ile FRAGIL ölçeği puan ortalaması arasındaki ilişkinin analiz sonuçları Tablo 3'te gösterilmektedir. Buna göre FRAGIL Ölçeği puan ortalamaları ile $\mathrm{mH} \& \mathrm{Y}$ evrelemesi arasında pozitif yönde bir ilişki $(p<0,001)$, hastalık süresi arasında negatif bir ilişki $(p=0,020)$, KFPB toplam puan ortalaması, KFPB denge, KFPB yürüme hızı puan ortalamaları ve KFPB alt ekstremite fonksiyonu arasında negatif bir ilişki saptanırken $(p<0,001$ ve $p=0,016)$, FRAGIL ölçeği ile el kavrama kuvveti ve yaş arasında ise herhangi bir ilişki görülmedi ( $\mathrm{p}>0,05)$. Ayrıca yaş ile el kavrama kuvveti arasında negatif yönde bir ilişki $(p=0,004)$, KFPB alt ekstremite fonksiyonu arasında ise pozitif bir ilişki 
Tablo 1. Katılımcıların sosyodemografik ve demografik özelliklerinin karşılaştırılması

\begin{tabular}{|c|c|c|c|c|}
\hline Değişkenler & $\begin{array}{c}\text { Kirılgan } \\
\text { olmayan grup } \\
(\mathbf{n}=6)\end{array}$ & $\begin{array}{l}\text { Kırılganlık öncesi } \\
\text { dönemde olan grup } \\
(n=47)\end{array}$ & Kırılgan grup $(n=15)$ & p \\
\hline $\begin{array}{l}\text { Yaş (yl), } \\
\text { Ort } \pm \text { SS (min-max) }\end{array}$ & $\begin{array}{l}69,17 \pm 1,33 \\
(67-70)\end{array}$ & $\begin{array}{l}71,91 \pm 8,49 \\
(56-82)\end{array}$ & $\begin{array}{l}68,73 \pm 7,22 \\
(58-79)\end{array}$ & $0,317^{\mathrm{a}}$ \\
\hline $\begin{array}{c}\text { Cinsiyet, n (\%) } \\
\text { Kadın } \\
\text { Erkek }\end{array}$ & $\begin{array}{c}0(0) \\
6(100)\end{array}$ & $\begin{array}{l}16(34) \\
31(66)\end{array}$ & $\begin{array}{c}5(33,3) \\
10(66,7)\end{array}$ & $0,230^{\mathrm{b}}$ \\
\hline $\begin{array}{l}\text { Vücut Kütle İndeksi (kg/m2), } \\
\text { Ort } \pm \text { SS (min-max) }\end{array}$ & $\begin{array}{c}27,54 \pm 3,15 \\
(22,49-32,45) \\
\end{array}$ & $\begin{array}{c}28,52 \pm 4,38 \\
(22,15-34,69) \\
\end{array}$ & $\begin{array}{c}27,20 \pm 2,07 \\
(22,81-29,14)\end{array}$ & $0,799^{\mathrm{a}}$ \\
\hline SMMT (0-30), Ort \pm SS (min-max) & $\begin{array}{l}26,67 \pm 2,42 \\
(22-28)\end{array}$ & $\begin{array}{c}24,76 \pm 3,96 \\
(16-30)\end{array}$ & $\begin{array}{l}24,73 \pm 2,19 \\
(22-29)\end{array}$ & $0,208^{\mathrm{a}}$ \\
\hline $\begin{array}{l}\text { Hastalık Süresi (ay), Ort } \pm \text { SS } \\
\text { (min-max) }\end{array}$ & $\begin{array}{c}112,00 \pm 43,38 \\
(24-132)\end{array}$ & $\begin{array}{c}94,98 \pm 62,57 \\
(12-240)\end{array}$ & $\begin{array}{c}40,27 \pm 27,69^{\# \dagger} \\
(12-180)\end{array}$ & $0,001^{\mathrm{a}}$ \\
\hline $\begin{array}{l}\text { Modifiye } \\
\text { Evrelemesi (1-4) } \\
\text { (min-max) }\end{array}$ & $\begin{array}{l}1,33 \pm 0,52 \\
(1-2)\end{array}$ & $\begin{array}{l}2,07 \pm 0,82 \\
\quad(1-3)\end{array}$ & $\begin{array}{l}2,73 \pm 1,13^{\dagger} \\
(1-4)\end{array}$ & $0,010^{\mathrm{a}}$ \\
\hline $\begin{array}{r}\text { Klinik alt tip, } \mathbf{n}(\%) \\
\text { Tremor baskın } \\
\text { Akinetik-rijit } \\
\text { Mikst } \\
\end{array}$ & $\begin{array}{c}2(33,3) \\
0 \\
4(66,7)\end{array}$ & $\begin{array}{c}9(19,2) \\
8(17,0) \\
30(63,8)\end{array}$ & $\begin{array}{c}1(6,7) \\
12(80) \\
2(13,3)^{¥ \dagger}\end{array}$ & $\mathbf{0 , 0 0 0 ^ { b }}$ \\
\hline
\end{tabular}

SMMT: Standardize Mini Mental Test.

$¥:$ Kırılgan grup ile Kırılganlık öncesi dönemde olan grup arasında fark vardır.

$\dagger:$ Kırılgan grup ile kırılgan olmayan grup arasında fark vardır.

†: a: Kruskal Wallis-H testi ile analiz edilmiştir.

b: Ki-kare testi ile analiz edilmiștir.

Tablo 2. Parkinson hastalarında kırılganlık fenotiplerine göre fiziksel fonksiyonun karşılaştırılması

\begin{tabular}{|c|c|c|c|c|c|c|c|}
\hline & \multirow[t]{2}{*}{ Gruplar } & \multirow[t]{2}{*}{$\mathbf{N}$} & \multirow[t]{2}{*}{$\begin{array}{l}\text { Siralar } \\
\text { Ortalaması }\end{array}$} & \multirow[t]{2}{*}{ Sd } & \multicolumn{2}{|c|}{ Kruskal Wallis H } & \multirow[t]{2}{*}{$\begin{array}{ll}\text { Fark } & \text { Olan } \\
\text { Gruplar } & \\
\end{array}$} \\
\hline & & & & & $X^{2}$ & $\mathrm{p}$ & \\
\hline \multirow[t]{3}{*}{$\begin{array}{l}\text { KFPB toplam } \\
(0-12)\end{array}$} & $\begin{array}{l}\text { Kirilgan } \\
\text { olmayan }\end{array}$ & 6 & 50,83 & 2 & 10,141 & 0,006 & $\begin{array}{l}\text { Kirılgan } \\
\text { olmayan- } \\
\text { Kirılgan }\end{array}$ \\
\hline & $\begin{array}{l}\text { Kirılganlık } \\
\text { öncesi } \\
\text { dönemde olan }\end{array}$ & 47 & 36,22 & & & & \\
\hline & Kirılgan & 15 & 22,57 & & & & \\
\hline \multirow{3}{*}{$\begin{array}{l}\text { KFPB } \\
\text { Alt ekstremite } \\
\text { fonksiyon (0- } \\
\text { 4) }\end{array}$} & $\begin{array}{l}\text { Kirılgan } \\
\text { olmayan }\end{array}$ & 6 & 56,25 & 2 & 9,338 & 0,009 & $\begin{array}{l}\text { Kirılgan } \\
\text { olmayan- } \\
\text { Kırılgan }\end{array}$ \\
\hline & $\begin{array}{l}\text { Kirılganlık } \\
\text { öncesi } \\
\text { dönemde olan }\end{array}$ & 47 & 33,64 & & & & $\begin{array}{l}\text { Kirılgan } \\
\text { olmayan- } \\
\text { Kirllganlık }\end{array}$ \\
\hline & Kırılgan & 15 & 28,50 & & & & $\begin{array}{l}\text { öncesi dönemde } \\
\text { olan }\end{array}$ \\
\hline \multirow[t]{3}{*}{$\begin{array}{l}\text { KFPB } \\
\text { Denge (0-4) }\end{array}$} & $\begin{array}{l}\text { Kirılgan } \\
\text { olmayan }\end{array}$ & 6 & 50,00 & 2 & 9,467 & 0,009 & $\begin{array}{l}\text { Kir1lgan } \\
\text { olmayan- } \\
\text { Kirılgan }\end{array}$ \\
\hline & $\begin{array}{l}\text { Kirılganlık } \\
\text { öncesi } \\
\text { dönemde olan }\end{array}$ & 47 & 35,78 & & & & \\
\hline & Kirılgan & 15 & 24,30 & & & & \\
\hline \multirow[t]{3}{*}{$\begin{array}{l}\text { KFPB } \\
\text { Yürüme } \\
(0-4)\end{array}$} & $\begin{array}{l}\text { Kirilgan } \\
\text { olmayan }\end{array}$ & 6 & 32,83 & 2 & 16,748 & $\mathbf{0 , 0 0 0}$ & $\begin{array}{l}\text { Kırılgan- } \\
\text { Kırılganlık } \\
\text { öncesi dönemde }\end{array}$ \\
\hline & $\begin{array}{l}\text { Kirılganlık } \\
\text { öncesi } \\
\text { dönemde olan }\end{array}$ & 47 & 40,22 & & & & olan \\
\hline & Kirılgan & 15 & 17,23 & & & & \\
\hline \multirow[t]{3}{*}{$\begin{array}{l}\text { El kavrama } \\
\text { kuvveti }(\mathrm{kg})\end{array}$} & $\begin{array}{l}\text { Kirilgan } \\
\text { olmayan }\end{array}$ & 6 & 47,83 & 2 & 4,111 & 0,128 & - \\
\hline & $\begin{array}{l}\text { Kirılganlık } \\
\text { öncesi } \\
\text { dönemde olan }\end{array}$ & 47 & 34,68 & & & & \\
\hline & Kirılgan & 15 & 28,60 & & & & \\
\hline
\end{tabular}


Tablo 3. Parkinson hastalarında kırılganlık ile fiziksel fonksiyon, sosyodemografik ve hastalık özellikleri arasındaki ilişki

\begin{tabular}{|c|c|c|c|c|c|c|c|c|c|}
\hline & $\begin{array}{l}\text { FRAGIL } \\
\text { Ölçeği }\end{array}$ & Yaş & $\mathrm{mH} \& \mathrm{Y}$ & $\begin{array}{l}\text { Hastalık } \\
\text { süresi }\end{array}$ & $\begin{array}{l}\text { KFPB } \\
\text { puanı }\end{array}$ & $\begin{array}{l}\text { KFPB } \\
\text { Alt } \\
\text { ekstremite } \\
\text { fonksiyon }\end{array}$ & $\begin{array}{l}\text { KFPB } \\
\text { Denge }\end{array}$ & $\begin{array}{l}\text { KFPB } \\
\text { Yürüme } \\
\text { h1z1 }\end{array}$ & $\begin{array}{l}\text { El } \\
\text { kavrama } \\
\text { kuvveti }\end{array}$ \\
\hline $\begin{array}{l}\text { FRAGIL } \\
\text { Ölçeği }\end{array}$ & - & & & & & & & & \\
\hline Yaş & $r=-0,192$ & - & & & & & & & \\
\hline $\mathrm{mH} \& \mathrm{Y}$ & $\mathrm{r}=0,487 * *$ & $\mathrm{r}=-0,085$ & - & & & & & & \\
\hline $\begin{array}{l}\text { Hastalık } \\
\text { süresi }\end{array}$ & $\mathrm{r}=-0,281^{*}$ & $\mathrm{r}=0,190$ & $\mathrm{r}=-0,123$ & - & & & & & \\
\hline KFPB puanı & $\mathrm{r}=-0,480 * *$ & $r=-0,125$ & $\mathrm{r}=-0,832 * *$ & $\mathrm{r}=-0,012$ & - & & & & \\
\hline $\begin{array}{l}\text { KFPB } \\
\text { Alt ekstremite } \\
\text { fonksiyon }\end{array}$ & $\mathrm{r}=-0,291^{*}$ & $\mathrm{r}=0,338 * *$ & $r=-0,646^{* *}$ & $r=-0,091$ & $\mathrm{r}=0,848 * *$ & - & & & \\
\hline $\begin{array}{l}\text { KFPB } \\
\text { Denge }\end{array}$ & $\mathrm{r}=-0,445^{* *}$ & $\mathrm{r}=0,138$ & $\mathrm{r}=-0,773 * *$ & $\mathrm{r}=0,125$ & $\mathrm{r}=0,823 * *$ & $\mathrm{r}=0,516^{* *}$ & - & & \\
\hline $\begin{array}{l}\text { KFPB } \\
\text { Yürüme hızı }\end{array}$ & $\mathrm{r}=-0,438^{* *}$ & $\mathrm{r}=-0,149$ & $\mathrm{r}=-0,586^{* *}$ & $\mathrm{r}=-0,097$ & $\mathrm{r}=0,764 * *$ & $\mathrm{r}=0,561 * *$ & $\mathrm{r}=0,402 * *$ & - & \\
\hline $\begin{array}{l}\text { El kavrama } \\
\text { kuvveti }\end{array}$ & $\mathrm{r}=-0,230$ & $\mathrm{r}=-0,349 * *$ & $\mathrm{r}=-0,199$ & $r=-0,063$ & $\mathrm{r}=0,384 * *$ & $\mathrm{r}=0,438 * *$ & $\mathrm{r}=0,038$ & $\mathrm{r}=0,540 * *$ & - \\
\hline
\end{tabular}

olduğu gösterildi $(\mathrm{p}=0,005)$. Benzer şekilde KFPB ve alt boyutları ile $\mathrm{mH} \& \mathrm{Y}$ arasında negatif yönlü bir ilişki tespit edildi $(\mathrm{p}<0,001)$. El kavrama kuvveti ile KFPB puan1, KFPB alt ekstremite fonksiyonu ve KFPB yürüme hızı arasında ise pozitif yönde bir ilişki mevcuttu $(\mathrm{p}<0,001)$ (Tablo 3).

\section{TARTIŞMA}

Bu çalışma, Parkinson Hastalarında kırılganlık ile fiziksel fonksiyon arasındaki ilişkiyi incelemek ve kırılganlık fenotiplerine göre Parkinson hastalarının fiziksel fonksiyon durumlarını da belirlemek amacıyla gerçekleştirildi. $\mathrm{Bu}$ çalışmaya katılan Parkinson hastalarının \%22,1'i kırılgan ve \%69,1'i ise kırılganlık öncesi dönemde iken hastaların \% 8,8'inde kırılganlık saptanmadı. Kırılgan Parkinson hastalarında hastalık şiddetinin daha fazla olduğu ve akinetik- rijit klinik alt tipin kırılgan Parkinson hastaları arasında daha yaygın olduğu gösterildi. Kırılgan Parkinson hastalarında genel fiziksel fonksiyonun, alt ekstremite fonksiyonunun, denge becerilerinin kırılgan olmayan hastalardan ve kırılganlık öncesi dönemde olan Parkinson hastalarından daha kötü olduğu ve yürüme hızının ise daha yavaş olduğu görüldü. Parkinson hastalarında kırılganlık ile alt ekstremite fonksiyonu, denge, yürüme hızı arasında negatif yönde ilişki mevcut iken, üst ekstremite fonksiyonu ile ilişki tespit edilmedi. Ayrıca kırılganlık ile hastalık şiddeti arasında pozitif yönde bir ilişki olduğu bunun yanında ilginç olarak hastalık süresi ile de negatif yönde bir ilişki olduğu belirlendi.

PH'nda fiziksel kırılganlık görülme oranının genel popülasyondan yüksek olduğu bilinmektedir. Yapılan prevelans çalışmalarında bu oranın Parkinson hastalarında \%29 ile \%67 arasında değiştiği bildirilmiştir (7). Bizim çalışmamızda ise Parkinson hastalarının \%22,1'inde kırılganlık görülürken, hastaların büyük bir çoğunluğunun $(\% 69,1)$ kırılganlık öncesi dönemde olduğu görüldü. Çalışmamızda saptadığımız oran literatürdeki çalışmalardan düşük olmakla beraber, PH'nda kırılganlığın yanısıra kırılganlık öncesi dönemde olan hasta sayısının yüksek olması çalışmanın çarpıcı bir bulgusu olarak ön plana çıkmaktadır. Parkinson hastalarının büyük bir çoğunluğunun kırılganlık öncesi dönemde olması bu grupta yer alan hastalar için değiştirtilebilir risk faktörlerinin belirlenerek ortadan kaldırılması ile PH'nda kırılganlığın geciktirilmesi, önlenmesi ya da kırılganlık etkilerinin en aza indirilmesi açısından hedef popülasyonun büyüklüğünü ortaya koymada önem taşımaktadır. Çalışmamızda kırılganlık prevelansının literatürdeki diğer çalışmalara nazaran düşük çıkmasından kırılganlık değerlendirilmesinde kullanılan ölçeklerin farklılık göstermesi sorumlu tutulabilir. Çalışmamızla benzer olarak Fried kriterlerini kullanan çalışmalarda kırılganlık oranının daha düşük olduğu, Rockwood ve Mitnitski tarafindan önerilen kümülatif defisitler indeksini kullanan çalışmalarda oranın yükseldiği bildirilmiştir $(8,9,19,20,21)$.

Parkinson hastalığında hastalık şiddetine bağlı olarak kırılganlık durumu değişebilir. Tan ve arkadaşları (22) hastalık şiddetinin arttığ 1 hastalarda kırılganlık görülme oranının daha fazla olduğunu göstermiştir. Lin ve arkadaşları (19) ise kırılgan Parkinson hastalarında hastalığın daha şiddetli olduğunu vurgulamıştır. Roland ve arkadaşları (8) hastalık şiddetinin fazla olmasının PH'nda kırılganlık açısından belirleyici olduğunu bildirmiştir. Bizim çalışmamızda da benzer olarak kırılganlık durumu ile birlikte hastalık şiddetinin değiştiği gösterilmiş olup kırılgan Parkinson hastalarının hastalığın daha ileri evresinde olduğu görülmektedir. Ayrıca kırılganlık fenotiplerine göre hastalığın klinik tip dağılımını incelediğimiz çalışmamızda kırılgan Parkinson hastalarının çoğunluğunun $(\% 80)$ akinetik- rijit tipte hastalığa sahip olduğu dikkat çekmektedir. Bu bulgu bize hastalığın akinetik-rijit tipte görülen yürüme güçlüğü ve postüral instabilite gibi motor semptomlarının PH'nda ortaya çıkan kırılganlığa katkısının olduğunu düşündürmüştür.

Literatürde, Parkinson hastalarında kırılganlık fenotiplerine göre fiziksel fonksiyon durumunu inceleyen ve kırılganlık ile fiziksel fonksiyon arasındaki ilişkiyi araştıran çalışma bulunmamaktadır. Daha önce yapılan sadece bir çalışmada kırılgan Parkinson hastalarında mobilitenin azaldığı, mobiliteyi değerlendiren süreli 
performans testlerinin süresinin uzadığı ve ZKYT'de 15,36 saniyenin Parkinson hastalarında kırılganlığ belirlemede bir kestirim noktası olabileceği bildirilmiştir (10). Çalışmamızda fiziksel fonksiyonun kırılganlık fenotiplerine göre değişiklik gösterdiği tespit edilmiştir. Buna göre alt ekstremite fonksiyonunun süreli bir performans testi olan "beş defa otur kalk testi" ile belirlendiği bu çalışmada, kırılgan Parkinson hastalarında bu sürenin uzamasına bağlı olarak testten alınan puanın kırılgan olmayan ve kırılganlık öncesi dönemdeki Parkinson hastalarına göre daha düşük olduğu, bununla birlikte kırılganlık öncesi dönemden itibaren alt ekstremite fonksiyonunun değişmeye başladığı görülmektedir. Hastalığın kardinal belirtilerinden olan bradikinezinin bu fonksiyon değişiminde rolü olduğunu düşünmekteyiz.

Günlük yaşam içerisinde hastaların fonksiyonelliğini sürdürebilmeleri için önemli olan denge becerilerini de değerlendiren bu çalışma, denge becerilerinin kırılgan Parkinson hastalarında kırılgan olmayan hastalara göre azaldığını göstermektedir. Kırılgan Parkinson hastalarının çoğunlukla akinetik-rijit klinik alt tipte olduğu ve bunun yanında hastalık şiddetinin bu hasta grubunda daha fazla olduğu göz önünde bulundurulursa çalışmadan elde edilen bu sonuç beklenilen bir durumdur. $\mathrm{Bu}$ çalışmada fiziksel fonksiyon başlığı altında ele alınan yürüme hızının kırılganlık için en önemli belirleyicilerden biri olduğu daha önceki çalışmalarda gösterilmiştir (23). Auyeung ve arkadaşları (24) 65 yaş ve üstü toplumda yaşayan bireyler üzerinde yaptıkları çalışmada yürüme hızının kırılganlığı tahmin etmede duyarlılığının ve özgüllüğünün yüksek olduğunu belirtmiştir. Ayrıca erkeklerde $0,9 \mathrm{~m} / \mathrm{s}^{\prime}$ den, kadınlarda ise $0,8 \mathrm{~m} / \mathrm{s}$ 'den düşük yürüme hızlarını bu popülasyonda kırılganlık taraması için kestirim değerleri olarak önermiştir. Benzer olarak Parkinson hastalarında da hem yürüme güçlükleri nedeni ile hem de kırılganlık sebebiyle yürüme hızı azalmaktadır. Peball ve arkadaşları (25) PH'nda yürüme hızı ile kırılganlık arasında ilişki olduğunu ve kırılgan olmayan Parkinson hastalarında ortalama yürüme hızı 1,3 $\pm 0.4 \mathrm{~m} / \mathrm{s}$ iken, kırılgan Parkinson hastalarında $0,9 \pm 0.4$ $\mathrm{m} / \mathrm{s}$ olduğunu bildirmiştir. Roland ve arkadaşları (20) ise çalışmalarında kırılganlık ile yürüme hızı arasında negatif yönde bir ilişkiye vurgu yapmıştır. Yaptığımız bu çalışmada 4 metre yürüme testi ile belirlediğimiz yürüme hızının, kırılgan Parkinson hastalarında kırılgan olmayan ile kırılganlık öncesi dönemde olan Parkinson hastalarına kıyasla azaldığını, aradaki farkın kırılganlık öncesi dönemde olan Parkinson hastaları ile kırılgan Parkinson hastaları arasında belirgin olduğunu gösterdik. Bununla birlikte Roland ve arkadaşlarının (20) çalışması ile tutarlı olarak bizim de çalışmamızda negatif yönde bir ilişki mevcuttu. $\mathrm{Bu}$ ilişki bize yürüme hızının azalma eğiliminde olduğu hastaların kırılganlık açısından risk altında olduğunu göstermektedir, bu bulguya dayanarak Parkinson hastalarında yürüme hızının korunması ya da artırılması yönünde planlanacak egzersiz programlarının PH'nda hem kırılganlığın hem de hastalığın motor bulgularına bağlı fonksiyonel düşüşün önlenmesinde etkili bir strateji olabileceğini düşünmekteyiz.

Üst ekstremite fonksiyonunu da ele aldığımız bu çalışmada el kavrama kuvveti kırılgan olmayan Parkinson hastalarında $18,67 \pm 2,58 \mathrm{~kg}$, kırılganlık öncesi dönemde olan Parkinson hastalarında 14,06 $\pm 5,97 \mathrm{~kg}$ ve kırılgan Parkinson hastalarında ise $12,47 \pm 7,44 \mathrm{~kg}$ olarak bulundu. Çalışmamızda her ne kadar kavrama kuvveti kırılganlıkla doğru orantılı olarak azalma eğiliminde de olsa gruplar arasında herhangi bir farklılı tespit edilmedi. Bunun paralelinde kırılganlık ile el kavrama kuvveti arasında da ilişki yoktu. Peball ve arkadaşları (25) ise bizim bulgularımızın aksine kavrama kuvvetinin kırılgan Parkinson hastalarında azaldığını gösterirken, Ahmedi ve arkadaşları (9) bizim çalışmamızda elde ettiğimiz bulguya benzer olarak kavrama kuvvetinin PH'nda kırılganlık durumuna göre değişmediğini bildirmiştir. Auyeung ve arkadaşları (24) kavrama kuvvetinin toplumda yaşayan yaşlı erkeklerde $28 \mathrm{~kg}$, kadınlarda $18 \mathrm{~kg}$ altında olmasını kırılganlık açısından belirleyici olduğunu göstermiştir. Bizim çalışmamız Auyeung ve arkadaşlarının (24) çalışmasını destekler nitelikte olup çalışmamızda hem kırılgan hem de kırılganlık öncesi dönemde olan Parkinson hastalarında belirlediğimiz ortalama kuvvet bu kestirim değerinin altındadır. Ancak kestirim değerinin altında olmasına rağmen el kavrama kuvveti açısından kırılganlık durumuna göre fark görülmemesinin nedeni kırılgan hastaların çoğunluğunun akinetik-rijit tipte hastalığa sahip olması dolayısıyla hastalığın motor semptomlarının çoğunlukla üst ekstremiteyi değil aksiyal fonksiyonları etkilemesi olabilir. Bu bulgu bize üst ekstremite fonksiyonundaki değişimde kırılganlık ve hastalık semptomlarının etkisinin içiçe geçmiş olduğunu ve yaşlı populasyonda kırılganlık için kavrama kuvveti belirleyici olsa da PH'nda kırılganlığı belirlemede kavrama kuvvetinin hastalığın klinik alt tipinin özellikleri ile etkileşime girme potansiyeline sahip olduğunu düşündürmüştür.

Parkinson hastalığında kırılganlık ile toplam fiziksel fonksiyon, alt ekstremite fonksiyonu, denge, yürüme hızı, hastalık şiddeti ve hastalık süresi arasında ilişkinin olduğunu gösteren bu çalışmada ilginç olarak kırılganlık ile hastalık süresi arasındaki ilişki negatif yöndeydi. Bu bulguyu hızlı ilerleme potansiyeline sahip akinetik-rijit tip PH dağılımının kırılgan Parkinson hastaları arasında yaygın olmasına bağlıyoruz. Buna göre hastalık tanılanma zamanı kısa bir süre de olsa akinetik-rijit tip PH'nda kırılganlık gelişebilir, bu sebeple akinetik rijit tip PH'nda hasta yeni tanı almış olsa da kırılganlık açısından değerlendirilmeli ve takip edilmelidir. Fiziksel fonksiyon ile kırılganlık arasındaki ilişki çalışmamızda negatif yöndedir. Yani fiziksel fonksiyonun düşüşü PH'nda kırılganlık görülme oranını ve şiddetini artırmaktadır. Tespit edilen ilişkiler, güç bakımından yordanacak olunursa alt ekstremite fonksiyonu ile kırılganlık arasında zayıf ilişki, kırılganlık ile toplam fiziksel fonksiyon, denge ve yürüme hızı arasında ise orta düzey bir ilişki olduğu görülmektedir.

Araştırmanın tek bir üniversite hastanesine belirli zaman diliminde başvuran ve çalışmaya katılmayı kabul eden hastalar ile yürütülmesi ve buna bağlı olarak yatağa bağımlı hastalara ulaşamamamız çalışmanın önemli limitasyonlarındandır. Yatağa bağımlı Parkinson hastalarının dahil edilememesi çalışmada kırılganlık prevelansını düşürmüş olabilir, ancak zaten bu çalışmanın odağı fiziksel fonksiyon olduğu için ve yatağa bağımlı hastalarda KFPB uygulanamayacağından bu sınırlılık göz 
ardı edilebilir. Yine de yatağa bağımlı hastaların da dahil edildiği, yatak içi fiziksel fonksiyonu değerlendiren yöntemlerin kullanıldığı çalışmalarda bu konu ele alınarak, elde edilen bulgular tüm popülasyona genellenebilir.

\section{SONUÇ}

$\mathrm{Bu}$ çalışmada incelediğimiz örneklem için kırılgan olan hastaların yanı sıra PH'nda kırılganlık öncesi dönemde olan hastaların da sayıca fazla olması önemli bir bulgudur. $\mathrm{Bu}$ çalışmadan elde edilen bulgular PH'nda kırılganlık fenotiplerine göre fiziksel fonksiyonun değiştiğini göstermektedir. Ayrıca bulgular Parkinson hastalarında kırılganlık ile toplam fiziksel fonksiyon, alt ekstremite fonksiyonu, denge ve yürüme hızının ilişkili oluğunu bunun yanısıra kırılganlık ile üst ekstremite fonksiyonu arasında ilişki olmadığını ortaya koymaktadır. Özellikle kırılganlık öncesi dönemde olan hastalar için kırılganlıkla ilişkili faktörlere yönelik geliştirilen uygun yaklaşımlar ve egzersiz programları ile kırılganlığın önüne geçilebilir veya saptadığımız bu faktörler PH'nda kırılganlık açısından risk altında olan hastaların belirlenmesinde ve takibinde yarar sağlayabilir. $\mathrm{Bu}$ sebeple PH'nda kırılganlık ile ilişkili faktörleri iyileştirmeye yönelik planlanacak tedavide bütüncül bir yaklaşımla nöroloğun, geriatristin ve fizyoterapistin iş birliği yapması ve kırılganlığı ele alması gerekmektedir.

Yazar Katkıları: Fikir/Kavram S.A.C., T.Ş.Ö.; Tasarım S.A.C., TŞÖ.; Veri Toplama ve/veya İşleme S.A.C., T.Ş.Ö.; Analiz ve/veya Yorum S.A.C.; Literatür Taraması S.A.C.; Makale Yazımı S.A.C.; Eleştirel İnceleme S.A.C., T.Ş.Ö.

\section{KAYNAKLAR}

1. Rodriguez-Manas L, Feart C, Mann G, Vina J, Chatterji S, Chodzko-Zajko W, et al. Searching for an operational definition of fragilty: A Delphi method based consensus statement: The fragilty operative definition-consensus conference project. J Gerontol A Biol Sci Med Sci. 2012; 68(1): 62-7.

2. Fried LP, Tangen CM, Walston J, Newman AB, Hirsch C, Gottdiener J, et al. Fragilty in older adults: evidence for a phenotype. J Gerontol A Biol Sci Med Sci. 2001; 56(3): 146-56.

3. Espinoza S, Walston JD. Fragilty in older adults: Insights and interventions. Cleve Clin J Med. 2005; 72(12): 1105-12.

4. Chen X, Mao G, Leng SX. Fragilty syndrome: An overview. Clin Interv Aging. 2014; 9: 433-41.

5. Collard RM, Boter H, Schoevers RA, Oude Voshaar RC. Prevalence of fragilty in community-dwelling older persons: a systematic review. J Am Geriatr Soc. 2012; 60(8): 1487-92.

6. Lally F, Crome P. Understanding fragilty. Postgrad Med J. 2007; 83(975): 16-20.

7. Smith N, Brennan L, Gaunt DM, Ben-Shlomo Y, Henderson E. Fragilty in Parkinson's disease: A systematic review. J Parkinsons Dis. 2019; 9(3): 517- 24.

8. Roland K, Jakobi J, Jones G, Powell C. Quality of life as a determinant of fragilty phenotype in community- dwelling persons with Parkinson's disease. J Am Geriatr Soc. 2012; 60(3): 590-2.

9. Ahmed NN, Sherman SJ, Vanwyck D. Fragilty in Parkinson's disease and its clinical implications. Parkinsonism Relat Disord. 2008; 14(4): 334-7.

10. Firat Özer F, Akın S, Gültekin M, Ertürk-Zararsız G, Ekinci-Soylu A. Fragilty in patients with Parkinson's disease: Associations with disability and timed up and go. Arch Neuropsychiatry. 2019. https://doi.org/10.29399/npa.23444 (in press).

11. Hughes AJ, Daniel SE, Kilfor L, Lees AJ. Accuracy of clinical diagnosis of idiopathic Parkinson's disease: a clinicopathological study of 100 cases. J Neurol Neurosurg Psychiatry. 1992; 55(3): 181-4.

12. Hoehn MM, Yahr MD. Parkinsonism: onset,progression, and mortality. Neurology. 1967; 17(5): 427-42.

13. Hymabaccus Muradi, Ben Azir Begum. Yaşlilarda kırılganlığı ölçmeye yönelik FRAGIL ölçeğinin Türkçe geçerlik ve güvenirlik çalışması [Uzmanlık Tezi]. Ankara: Hacettepe Üniversitesi; 2017.

14. Morley JE, Malmstrom TK, Miller DK. A simple fragilty questionnaire (FRAGIL) predicts outcomes in middle aged African Americans. J Nutr Health Aging. 2012; 16(7): 601-8.

15. Guralnik JM, Simonsick EM, Ferrucci L, Glynn RJ, Berkman LF, Blazer DG, et al. A short physical performance battery assessing lower extremity function: association with self-reported disability and prediction of mortality and nursing home admission. $\mathbf{J}$ Gerontol Med Sci. 1994; 49(2): 85-94.

16. Fisher S, Ottenbacher KJ, Goodwin JS, Graham JE, Ostir GV. Short Physical Performance Battery in hospitalized older adults. Aging Clin Exp Res. 2009; 21(6): 445-52.

17. Fess E. Grip strength. In Casanova JS editor. Clinical assessment recommendations. 2nd ed. Chicago: American Society of Hand Therapists; 1992. p. 41-5.

18. Roberts HC, Denison HJ, Martin HJ, Patel HP, Syddall H, Cooper C, et al. A review of the measurement of grip strength in clinical and epidemiological studies: towards a standardised approach. Age Ageing. 2011; 40(4): 423- 9.

19. Lin WC, Huang YC, Leong CP, Chen MH, Chen HL, Tsai NW, et al. Associations between cognitive functions and physical fragilty in patients with Parkinson's disease. Front Aging Neurosci. 2019; 11: 283.

20. Roland K, Cornett K, Theou O, Jakobi J, Jones G. Physical activity across fragilty phenotypes in females with Parkinson's disease. J Aging Res. 2012: 468156.

21. Roland K, Cornett K, Theou O, Jakobi J, Jones G. Concurrence of fragilty and Parkinson's disease. J Fragilty Aging. 2012; 1(3): 123-7.

22. Tan AH, Hew YC, Lim SY, Ramli NM, Kamaruzzaman SB, Tan MP, et al. Altered body composition, sarcopenia, fragilty, and their clinicobiological correlates, in Parkinson's disease. Parkinsonism Relat. Disord. 2018; 56: 58-64.

23. Hoogendijk EO, Abellan van Kan G, Guyonnet S, Vellas B, Cesari M. Components of the fragilty phenotype in relation to the fragilty index: results 
from the Toulouse Fragilty Platform. J Am Med Dir Assoc. 2015; 16(10): 855-9.

24. Auyeung TW, Lee JS, Leung J, Kwok T, Woo J. The selection of a screening test for fragilty identification in community-dwelling older adults. J Nutr Health Aging. 2014; 18(2): 199-203.

25. Peball M, Mahlknecht P, Werkmann M, Marini K, Murr F, Herzmann H, et al. Prevalence and associated factors of sarcopenia and fragilty in Parkinson's disease: A cross-sectional study. Gerontology. 2019; 65(3): 216-28. 